\title{
COMMUNICATION
}

\section{T Cell Force-Responsive Delivery of Anticancer Drugs Using Mesoporous Silica Microparticles}

Received 00th January 20xx, Accepted 00th January 20xx

DOI: $10.1039 / \mathrm{x} 0 \mathrm{xx} 00000 \mathrm{x}$

\author{
Kewen Lei, ${ }^{a}$ and Li Tang*ab
}

T cell-based cancer immunotherapy has achieved great success in the clinic; however, only a small fraction of patients respond to this therapy. Strategies to specifically and safely augment anticancer activity through controlled delivery of $T$ cell supporting factors or drugs for combinatory therapy remain of high interest. Here, we devised a T cell force-responsive system for selective delivery of anticancer drugs using a mesoporous silica microparticle capped with a DNA force sensor. Upon T cell receptor (TCR) triggering, T cells exerted synaptic forces, a unique biophysical stimulus, to rupture the force-sensitive DNA gatekeepers on the mesopores leading to a rapid drug release. Our results demonstrated that this cellular force-responsive system specifically released anticancer drugs in a $T$ cell force-dependent manner and significantly enhanced cancer cell killing in vitro and in vivo. This work opens a new horizon toward designing next-generation drug delivery systems in response to signaling-specific cellular forces.

Spatiotemporally controlled drug delivery using stimulus-responsive release system can improve the specificity of various therapeutics including anticancer drugs. ${ }^{1,2}$ Among the diverse stimuli explored to date, biochemical signals dominate, such as $\mathrm{pH}^{3-5}$ redox potential, ${ }^{6-}$ 8 enzymes, ${ }^{9-11}$ and reactive oxygen species. ${ }^{12-14}$ Nevertheless, biophysical signals, such as mechanical forces, are garnering increasing attention due to their ubiquitous existence in human body. ${ }^{15-17}$ Exertion or alteration of bio-mechanical forces has been reported to be associated with specific biological processes or pathologies. ${ }^{18,19}$ For instance, shear stress in constricted vessels of atherosclerotic patients increases significantly providing a potential disease-specific stimulus for targeted drug delivery. ${ }^{20}$ In addition to the mechanical forces at the tissue level, cells exert rapid and strong cellular forces. For example, myofibroblasts exert traction forces for remodeling extracellular matrix (ECM) during wound healing. ${ }^{21}$ Recently, cytotoxic T cells were found to exert significant mechanical forces specifically at the immunological synapse upon antigen recognition / T cell receptor (TCR) activation to potentiate the killing of target cells in addition to the secreted cytolytic enzymes. ${ }^{22}$

Cytotoxic T cells are among the most important effector cells in cancer immunotherapy. ${ }^{23,24}$ Approaches to safely and effectively supplement $T$ cells with supporting drugs to enhance immunotherapy or other therapeutics for combination therapy remain of great interest. In the previous work, we reported a T cell surface-conjugated nanogel that responded to an increase in T cell surface reduction potential upon tumor antigen recognition. ${ }^{7}$ The release of cytokines in nanogel was therefore controlled by TCR activation and restricted to sites of cognate antigen encounter, such

T cell force-responsive drug release

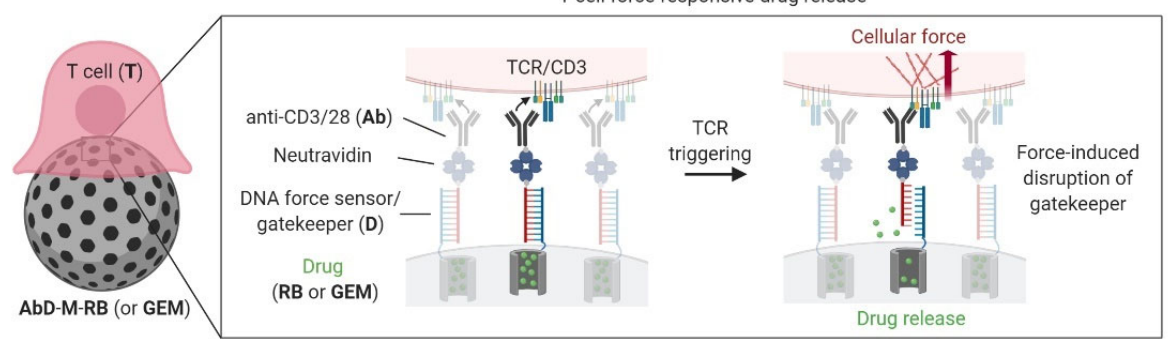

Figure 1. Schematic of T cell force-responsive drug release system based on a mesoporous silica microparticle (M) capped with DNA force sensors (D). TCR, T cell receptor; Ab, anti-CD3 and anti-CD28 antibodies; RB, rhodamine B; GEM, gemcitabine.

\footnotetext{
a. Institute of Materials Science \& Engineering, École polytechnique fédérale de Lausanne (EPFL), Lausanne, Switzerland, $\mathrm{CH}-1015$

b. Institute of Bioengineering, École polytechnique fédérale de Lausanne (EPFL), Lausanne, Switzerland, $\mathrm{CH}-1015$

*E-mail: li.tang@epfl.ch

+ Footnotes relating to the title and/or authors should appear here.

Electronic Supplementary Information (ESI) available: [details of any supplementary

information available should be included here]. See DOI: 10.1039/x0xx00000x
}

as the tumor microenvironment, leading to greatly enhanced efficacy and safety in adoptive T cell therapy. However, this approach relies on a relatively slow-responding and diffusive biochemical signal as the trigger, i.e. cell surface reduction potential. 
Cellular force exerted by cytotoxic T cell upon TCR activation by cognate antigen is a highly specific and instantaneous mechanical stimulus. We therefore exploit the T cell force as a unique biophysical trigger to achieve TCR signaling-responsive drug delivery. However, it remains challenging to design and obtain a triggered release system in response to cellular forces as they are in extremely small ranges (nanonewton). Here, we describe a T cell force-responsive platform for anticancer drug delivery using a drug-loaded mesoporous silica microparticle (M) capped with double-strand DNA (D) as a force-sensitive gatekeeper (Figure 1). One of the DNA strands was linked to anti-CD3 and anti-CD28 antibodies (Ab), which bound to $T$ cell surface and triggered TCR signaling. Upon TCR triggering by the stimulatory antibodies, $T$ cells exerted cellular forces that disrupted the DNA gatekeepers leading to a rapid drug release from uncapped mesopores. Using rhodamine B (RB) as a model drug, we demonstrated the drug release was controlled by $T$ cell forces. When loaded with an anticancer drug, gemcitabine (GEM), T cell forceresponsive drug release enhanced the killing efficiency of cancer cells in vitro and in vivo.

We first designed a DNA force sensor that is sensitive to cellular forces that are estimated to be dozens of piconewton $(\mathrm{pN})$ per receptor (Figure S1a). ${ }^{25}$ According to a previous report, the double strand DNA structure with a sequence of 15 nucleotide pairs could be ruptured by a force of $\sim 50 \mathrm{pN}, 26,27$ which is within the range of force per TCR generated by T cells. ${ }^{28}$ The sensor is a self-assembly of two complementary DNA strands, an anchor strand bearing an amino group for conjugation to the surface of microparticles, and a capper strand bearing a biotin molecule for coupling to antibodies through the biotin/neutravidin interaction. The assembly structure was confirmed by gel electrophoresis showing resistance to a singlestrand nucleic acid-specific nuclease (Figure S1b).

a

\begin{tabular}{lllll}
\hline & $\begin{array}{l}\text { Particle } \\
\text { diameter } \\
(\mu \mathrm{m})\end{array}$ & $\begin{array}{l}\text { Zeta- } \\
\text { potential } \\
(\mathrm{mV})\end{array}$ & $\begin{array}{l}\text { DNA } \\
\text { density } \\
(\mathrm{nmol} / \mathrm{g})\end{array}$ & $\begin{array}{l}\text { Antibody } \\
\text { density } \\
(\mathrm{nmol} / \mathrm{g})\end{array}$ \\
\hline M & $3.74 \pm 0.2$ & $-17.8 \pm 3.4$ & $/$ & $/$ \\
$\mathrm{D}-\mathrm{M}$ & $3.93 \pm 0.4$ & $-18.8 \pm 0.2$ & $10.9 \pm 3.3$ & $/$ \\
AbD-M & $4.27 \pm 0.2$ & $-14.1 \pm 3.4$ & $10.9 \pm 3.3$ & $4.26 \pm 0.1$ \\
\hline
\end{tabular}
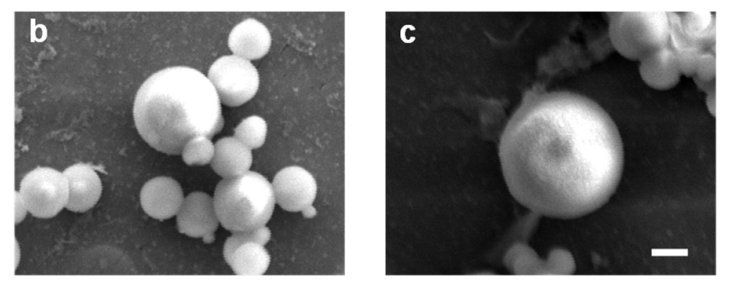

Figure 2. (a) Summarized physicochemical properties of $\mathbf{M}, \mathbf{D}-\mathbf{M}$, and AbD-M. Data are mean \pm s.d. (b, c) Scanning electron microcopy (SEM) images of $\mathbf{M}(\mathbf{b})$ and $\mathbf{A b D}-\mathbf{M}$ (c). Scale bar, $500 \mathrm{~nm}$.

Next, commercially purchased Ms with pore size around $3 \mathrm{~nm}$ were functionalized with isocyanate groups using (3isocyanatopropyl)triethoxysilane (Figure S2).29 The amount of isocyanate groups on surface was measured by elemental analysis and determined to be $9.86 \mathrm{mmol} / \mathrm{g}$ (Table S1). The DNA force sensor was next immobilized on the surface of $\mathbf{M}$ through the amidation reaction between amino and isocyanate groups to afford DNAfunctionalized silica microparticles (denoted as D-M, Figure S2). Successful conjugation of DNA to $\mathbf{M}$ was confirmed by the UV-vis spectrometer (Figure S3a) and the amount of $\mathbf{D}$ was quantified by the absorbance at $260 \mathrm{~nm}(10.9 \pm 0.3 \mathrm{nmol} / \mathrm{g}$, Figure 2a; Figure S3b). To further functionalize $\mathbf{D}-\mathbf{M}$ with antibodies, $\mathbf{D}-\mathbf{M}$ was incubated in an aqueous solution of neutravidin followed by addition of biotinylated anti-CD3 and anti-CD28 antibodies (Figure S2). The total amount of conjugated $\mathbf{A b}$ on $\mathbf{A} \mathbf{b}$-functionalized $\mathbf{D}-\mathbf{M}$ (denoted as $\mathbf{A b D}-\mathbf{M}$, Figure S3) was determined to be $4.26 \pm 0.1 \mathrm{nmol} / \mathrm{g}$ using bicinchoninic acid protein assay (Figure $2 \mathrm{a}$ ). The AbD-M has an average hydrodynamic diameter of $4.27 \pm 0.2 \mu \mathrm{m}$ and zeta potential of $-14.1 \pm 3.4 \mathrm{mV}$ (Figure 2a). The AbD-M maintained a spherical morphology similar to that of $\mathbf{M}$ as imaged by scanning electron microscopy (Figure $2 b, c$ ).

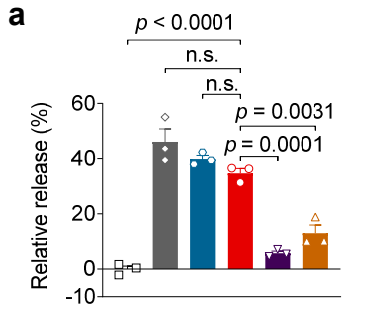

b

$$
\begin{aligned}
& -T+\text { sol. Ab + D-M-RB } \\
& -T+\text { AbD-M-RB }
\end{aligned}
$$
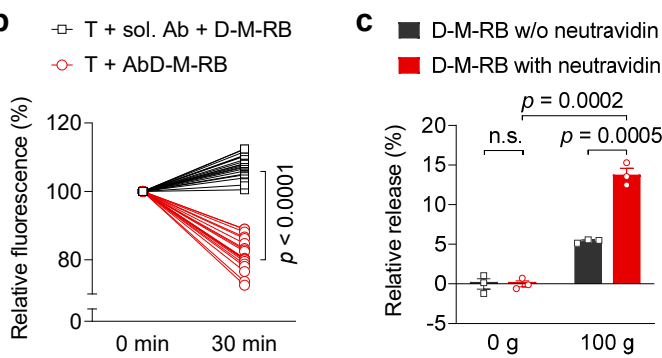

Figure 3. (a) Relative release profiles of rhodamine $B$ (RB) from indicated systems after $1.5-\mathrm{h}$ incubation at $37^{\circ} \mathrm{C}(\mathrm{n}=3)$. (b) Relative fluorescence intensity of $\mathbf{A b D}-\mathbf{M}-\mathbf{R B}$ and $\mathbf{D}-\mathbf{M}-\mathbf{R B}+$ sol. $\mathbf{A b}$ after incubation with T cells (T) for $30 \mathrm{~min}(\mathrm{n}=20)$. (c) Relative release of RB from D-M-RB upon centrifugal forces with or without neutravidin conjugation $(n=3)$.

To investigate the $\mathrm{T}$ cell force-responsive release of the designed system, we pre-loaded $\mathbf{M}$ with $\mathbf{R B}$, a fluorescent model drug, to prepare AbD-M-RB (Figure S2). The loading amount of RB was 157.7 $\mu \mathrm{mol} / \mathrm{g}$ according to the fluorescence intensity measurement (Table S2 and Figure S4a). By subtracting the background release from AbDM-RB due to nonspecific leakage, ${ }^{30}$ we showed that uncapped M-RB (Figure S2) exhibited a relative release of $46.8 \%$ (Figure $3 a$ and Figure S5). Upon treatment with DNase I, a DNA degradation enzyme, the relative release of $\mathbf{R B}$ from $\mathbf{A b D}-\mathbf{M}-\mathbf{R B}$ was complete and comparable with that from uncapped M-RB (Figure 3a), suggesting the successful capping of the mesopores by the DNA force sensors. We next cocultured AbD-M-RB with activated Pmel CD8 ${ }^{+}$T cells (T + AbD-M-RB), which, as expected, triggered a rapid release of loaded RB (35.5 \%, Figure $3 a$ and Figure S5). The triggered release was TCR signalingdependent as replacing the stimulatory antibodies with an isotype antibody control resulted in minimum release of $\mathbf{R B}$ (Figure S6a). Confocal imaging analysis of $\mathrm{T}$ cells co-cultured with fluorescently labeled AbD-M revealed a negligible level of internalization of the microparticles (Figure S6b) suggesting that the observed drug release 
was not due to particle internalization by T cells or DNA gatekeeper digestion intracellularly. This observation is consistent with the previous reports that $T$ cells are less phagocytotic, in particular, toward large particles. ${ }^{31,32}$

To validate that the $\mathbf{A b}$-mediated physical rupture of DNA gatekeeper contributed to the RB release, we next replaced the conjugated $\mathbf{A b}$ with soluble antibodies for triggering TCR activation of T cells $(\mathbf{T}+$ sol. $\mathbf{A} \mathbf{b}+\mathbf{D}-\mathbf{M}-\mathbf{R B})$. As the DNA force sensor was not connected to sol. Ab to relay $\mathrm{T}$ cell forces, the gatekeepers remained intact and thereof the observed release of RB was minimum (6.5\%, Figure 3a) as compared to that from T + AbD-M-RB. Next, we performed a time-lapse fluorescence imaging study to monitor the change of fluorescence intensity of RB in AbD-M-RB in the presence of activated Pmel $\mathrm{CD}^{+} \mathrm{T}$ cells. A rapid decrease of fluorescence intensity was noticed from AbD-M-RB within $\mathbf{3 0}$ min as released RB quickly diffused away (Figure $3 \mathrm{~b}$; Figure S7 and Movie S1). On contrast, sol. Ab + D-M-RB displayed negligible fluorescence decay even in the presence of activated T cells (Figure 3b; Figure S7 and Movie S2). Together, soluble stimulatory antibodies failed to trigger the drug release implying the physical connection of $T$ cells to the DNA gatekeepers was necessary and the triggered drug release was not mediated by any soluble biochemical factors secreted by $T$ cells upon TCR activation.

In order to directly examine the role of $\mathrm{T}$ cell force, we next cocultured AbD-M-RB with activated Pmel CD8 ${ }^{+} \mathrm{T}$ cells pretreated with Latrunculin $A$, a small molecule inhibitor that inhibits actin polymerization and therefore the generation of cellular forces. By inhibiting the $T$ cell forces, the release of RB was significantly suppressed (13\%, Figure 3a). In addition, we applied centrifugal force on D-M-RB to mimic the T cell forces in another in vitro release assay (Figure S8). Centrifugation has been widely used to apply controlled forces on cells for studying cell adherence. ${ }^{33}$ When $\mathbf{D}-\mathbf{M}$ RB was conjugated to the well bottom via neutravidin, markedly increased release of RB was observed under centrifugal force (100 g, $2 \mathrm{~min}$ ) as compared to static condition ( $0 \mathrm{~g}$ ) (Figure $3 \mathrm{c}$ ). These results suggest that the triggered cargo release in AbD-M-RB was mediated by $\mathrm{T}$ cell forces.

a

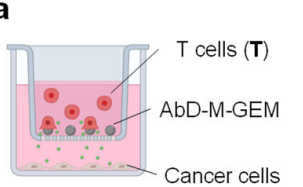

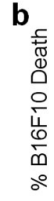

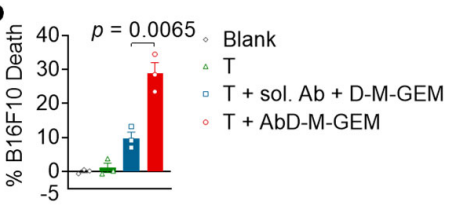

C
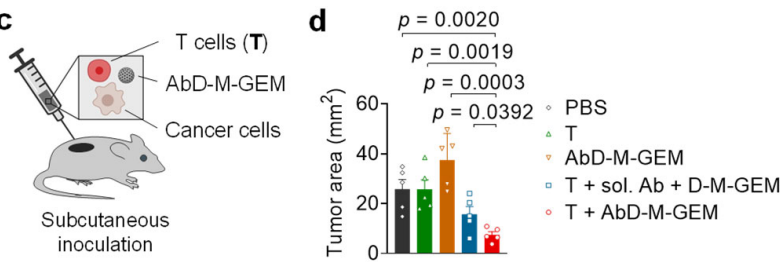

Figure 4. (a) Schematic of an in vitro release assay with transwell. (b) Percentage of B16F10 cell death upon the indicated treatment in the upper chamber $(n=3)$. (c) Schematic of an in vivo cancer prevention assay. (d) Tumor areas at day 7 post inoculation of MC38 cancer cells mixed with indicated reagents ( $n=5$ mice per group).
Next, we loaded the T cell force-responsive microparticle with GEM (denoted as AbD-M-GEM, Figure S2) to assess its efficiency in killing cancer cells. The loading capacity of GEM in AbD-M-GEM was determined by UV absorbance $(670 \mu \mathrm{mol} / \mathrm{g}$, Table S2 and Figure S4b). In order to evaluate the sole effect of released anticancer drug and exclude the killing effect mediated by T cells, which requires physical contact between a T cell and a target cell (immunological synapse formation), we performed the cancer cell killing assay in a transwell plate allowing the transfer of small molecules but not cells from the upper to the bottom chambers (Figure 4a). AbD-M-GEM was cocultured with activated Pmel $\mathrm{CD}^{+} \mathrm{T}^{\mathrm{T}}$ cells in the upper well while B16F10 cancer cells, a murine melanoma cell line, were seeded in the bottom well. No cancer cell killing was noticed with $T$ cell alone (Figure 4b). However, in the presence of T cells, AbD-M-GEM led to markedly increased efficiency of cancer cell killing (28.8\%, Figure $4 \mathrm{~b})$ due to the rapid release of GEM triggered by $T$ cell forces. Consistently, sol. Ab + D-M-GEM in the presence of T cells resulted in a significantly lower percentage of cancer cell killing (9.8\%, Figure $4 \mathrm{~b})$ as the drug release was inefficient. It is worth noting that AbDM-GEM exhibited minimal toxicity against the T cells $(3.5 \%$ of apoptosis induced as shown in Figure S9a).

To further assess the efficacy in vivo, we next established a tumor prevention model by subcutaneously co-injecting MC38, a murine colon carcinoma cell, together with activated Pmel $\mathrm{CD}^{+} \mathrm{T}$ cells + AbD-M-GEM in mice (Figure 4c). As the antigen recognized by Pmel CD8 ${ }^{+} \mathrm{T}$ cells (glycoprotein 100 ) is not expressed in MC38 cancer cells, $T$ cell alone resulted in no influence on tumor growth (Figure $4 \mathrm{~d}$ and Figure S9b). AbD-M-GEM alone failed to control the tumor growth either because anticancer drug release was not triggered. While $T$ cells plus sol. Ab + D-M-GEM showed certain effect of tumor growth inhibition, T cells plus AbD-M-GEM markedly suppressed the tumor progression in mice with 3.5-fold smaller tumor size compared to that of the PBS treatment 7 days post injection, showing superior anticancer efficacy in vivo (Figure $4 d$ ).

\section{Conclusions}

In summary, we demonstrated, for the first time, a T cell forceresponsive delivery system for anticancer drugs. The cellular forcemediated drug release was highly specific and controlled by TCR activation of T cells, leading to efficient killing of cancer cells in vitro and in vivo. The DNA mechano-sensor was crucial to respond sensitively to the cellular forces that are in a very small scale. ${ }^{25}$ Integrin binding aptamer has recently been reported as a mechanosensor to control the release of growth factors in response to random cellular traction forces. ${ }^{34}$ By using the functionalized mesoporous silica microparticles, we chemically linked the force-triggered drug delivery to a specific cell signaling (i.e., TCR activation of T cells) to achieve cell-signaling-controlled drug release and therefore high specificity. In addition, loading of drugs in mesopores through physical encapsulation allows for a high versatility for various therapeutics. By adopting mesoporous silica microparticles with suitable pore sizes, a wide range of cargos including small molecules, peptides, cytokines, and antibodies could be potentially loaded in this cellular force-responsive delivery system. ${ }^{35,36}$ Cellular forces controlled by specific cell signaling are widely involved in both innate and adaptive immunity. ${ }^{37,38}$ This cellular force-responsive system has the promise to be coupled with various immune cells for synergistic 
and enhanced cancer therapies. Toward potential translational applications, several challenges remain, such as miniaturizing the system down to nanosize for systemic administration, and fine tuning the sensitivity of the force-responsive gatekeeper to ensure sufficiency as well as specificity of drug release.

\section{Conflicts of interest}

There are no conflicts to declare.

\section{Acknowledgements}

We thank Dr. Maartje Bastings (EPFL) for her input on the design of DNA gatekeeper. L.T. gratefully acknowledges grant support from the Swiss National Science Foundation (Project grant 315230_173243) and European Research Council (ERC starting grant 805337).

\section{References}

1 E. Fleige, M. A. Quadir and R. Haag, Adv. Drug Deliv. Rev., 2012, 64, 866-884.

2 Y. Lu, W. Sun and Z. Gu, J. Control. Release, 2014, 194, 119.

3 H. Meng, M. Xue, T. Xia, Y. L. Zhao, F. Tamanoi, J. F. Stoddart, J. I. Zink and A. E. Nel, J. Am. Chem. Soc., 2010, 132, 12690-12697.

4 J. Su, F. Chen, V. L. Cryns and P. B. Messersmith, J. Am. Chem. Soc., 2011, 133, 11850-11853.

5 Z. Li, D. L. Clemens, B. Y. Lee, B. J. Dillon, M. A. Horwitz and J. I. Zink, ACS Nano, 2015, 9, 10778-10789.

6 M. Wu, Q. Meng, Y. Chen, L. Zhang, M. Li, X. Cai, Y. Li, P. Yu, L. Zhang and J. Shi, Adv. Mater., 2016, 28, 1963-1969.

7 L. Tang, Y. Zheng, M. B. Melo, L. Mabardi, A. P. Castaño, Y. Q. Xie, N. Li, S. B. Kudchodkar, H. C. Wong, E. K. Jeng, M. V. Maus and D. J. Irvine, Nat. Biotechnol., 2018, 36, 707-716.

8 Y. Q. Xie, H. Arik, L. Wei, Y. Zheng, H. Suh, D. J. Irvine and L. Tang, Biomater. Sci., 2019, 7, 1345-1357.

9 K. Patel, S. Angelos, W. R. Dichtel, A. Coskun, Y. W. Yang, J. I. Zink and J. F. Stoddart, J. Am. Chem. Soc., 2008, 130, 2382-2383. H. Han, D. Valdepérez, Q. Jin, B. Yang, Z. Li, Y. Wu, B. Pelaz, W. J. Parak and J. Ji, ACS Nano, 2017, 11, 1281-1291. B. Wang, S. Van Herck, Y. Chen, X. Bai, Z. Zhong, K. De Swarte, B. N. Lambrecht, N. N. Sanders, S. Lienenklaus, H. W. Scheeren, S. A. David, F. Kiessling, T. Lammers, B. G. De Geest and Y. Shi, J. Am. Chem. Soc., 2020, 142, 1213312139.

12 E. A. Scott, A. Stano, M. Gillard, A. C. Maio-Liu, M. A. Swartz and J. A. Hubbell, Biomaterials, 2012, 33, 6211-6219.

13 Y. Li, Y. Li, W. Ji, Z. Lu, L. Liu, Y. Shi, G. Ma and X. Zhang, J. Am. Chem. Soc., 2018, 140, 4164-4171.

14 Q. Chen, G. Chen, J. Chen, J. Shen, X. Zhang, J. Wang, A. Chan and Z. Gu, Nano Lett., 2019, 19, 4879-4889.

15 J. Barthes, D. Mertz, C. Bach, M. H. Metz-Boutigue, B. Senger, J. C. Voegel, P. Schaaf and P. Lavalle, Langmuir,

2012, 28, 13550-13554.

16

17
Y. Zhang, J. Yu, H. N. Bomba, Y. Zhu and Z. Gu, Chem. Rev., 2016, 116, 12536-12563.

J. Wang, J. A. Kaplan, Y. L. Colson and M. W. Grinstaff, Adv. Drug Deliv. Rev., 2017, 108, 68-82.

P. F. Davies, Nat. Clin. Pract. Cardiovasc. Med., 2009, 6, 1626.

R. Agha, R. Ogawa, G. Pietramaggiori and D. P. Orgill, J. Surg. Res., 2011, 171, 700-708.

M. N. Holme, I. A. Fedotenko, D. Abegg, J. Althaus, L. Babel, F. Favarger, R. Reiter, R. Tanasescu, P. L. Zaffalon, A. Ziegler, B. Müller, T. Saxer and A. Zumbuehl, Nat. Nanotechnol., 2012, 7, 536-543.

J. J. Tomasek, G. Gabbiani, B. Hinz, C. Chaponnier and R. A. Brown, Nat. Rev. Mol. Cell Biol., 2002, 3, 349-363.

R. Basu, B. M. Whitlock, J. Husson, A. Le Floc'h, W. Jin, A. Oyler-Yaniv, F. Dotiwala, G. Giannone, C. Hivroz, N. Biais, J. Lieberman, L. C. Kam and M. Huse, Cell, 2016, 165, 100110.

P. G. Coulie, B. J. Van Den Eynde, P. Van Der Bruggen and T. Boon, Nat. Rev. Cancer, 2014, 14, 135-146.

A. Durgeau, Y. Virk, S. Corgnac and F. Mami-Chouaib, Front Immunol., 2018, 9, 14.

P. Roca-Cusachs, V. Conte and X. Trepat, Nat. Cell Biol., 2017, 19, 742-751.

X. Wang and T. Ha, Science, 2013, 340, 991-994.

F. Chowdhury, I. T. S. Li, B. J. Leslie, S. Dolanay, R. Singh, X. Wang, J. Seong, S. H. Lee, S. Park, N. Wang and T. Ha, Integr. Biol., 2015, 7, 1265-1271.

Y. Liu, L. Blanchfield, V. P.-Y. Ma, R. Andargachew, K. Galior, Z. Liu, B. Evavold and K. Salaita, Proc. Natl. Acad. Sci., 2016, 113, 5610-5615.

L. Pascual, I. Baroja, E. Aznar, F. Sancenón, M. D. Marcos, J. R. Murguía, P. Amorós, K. Rurack and R. Martínez-Máñez, Chem. Commun., 2015, 51, 1414-1416.

Y. Zhang, Q. Yuan, T. Chen, X. Zhang, Y. Chen and W. Tan, Anal. Chem., 2012, 84, 1956-1962.

M. T. Stephan, J. J. Moon, S. H. Um, A. Bershteyn and D. J. Irvine, Nat. Med., 2010, 16, 1035-1041.

F. S. Majedi, M. M. Hasani-Sadrabadi, T. J. Thauland, S. Li, L. S. Bouchard and M. J. Butte, Nano Lett., 2019, 19, 69456954.

J. W. Piper, R. A. Swerlick and C. Zhu, Biophys. J., 1998, 74, 492-513.

A. Stejskalová, N. Oliva, F. J. England and B. D. Almquist, Adv. Mater., 2019, 31, 1806380

J. Tu, A. L. Boyle, H. Friedrich, P. H. H. Bomans, J. Bussmann, N. A. J. M. Sommerdijk, W. Jiskoot and A. Kros, ACS Appl. Mater. Interfaces, 2016, 8, 32211-32219. A. Noureddine, A. Maestas-olguin, E. A. Saada, A. E. Labauve, J. O. Agola, K. E. Baty, T. Howard, J. K. Sabo, C. R. Sandoval, J. A. Doudna, J. S. Schoeniger, K. S. Butler, O. A. Negrete, C. J. Brinker and R. E. Serda, Acta Biomater., 2020, 114, 358-368.

J. E. Molloy and P. Tolar, Science, 2013, 340, 1587-1590.

J. Wang, H. Chen, T. Hang, Y. Yu, G. Liu, G. He, S. Xiao, B. Yang, C. Yang, F. Liu, J. Tao, M. X. Wu and X. Xie, Nat. 
Nanotechnol., 2018, 13, 1078-1086. 